\title{
LA DICTADURA DE LA CONCIENCIA
}

Bernard N. Schumacher*

RESUMEN: La reflexión relativa al llamado imperativo a seguir el dictamen de la conciencia - y no sacrificarla a ningún interés particular ni instancia exterior - debe tomar siempre en cuenta las exigencias planteadas "por la alteridad del mundo" y, sobre todo, por aquellas de la verdad. La palabra debe servir no para justificar ninguna especie de tiranía, sino para hacer presente la verdad.

$$
\text { শ্ৰ }
$$

\section{THE DICTATORSHIP OF CONSCIENCE}

ABSTRACT: Reflection on the imperative call of acting as our conscience dictates - despite the pressure of individual interests or external influence - must always take into account the demands raised "by the otherness of the world" and, above all, those raised by the truth. The word must serve not to justify any kind of tyranny, but rather, make the truth present.

PALABRAS CLAVE: conciencia moral, obligación, responsabilidad, totalitarismo, autonomía, dignidad, subjetivismo, intolerancia.

KEY WORDS: moral conscience, obligation, responsibility, totalitarianism, autonomy, dignity, subjectivism, intolerance.

RECEPCIÓN: 13 de diciembre de 2017.

APROBACIÓN: 15 de mayo de 2018

* Universidad de Friburgo, Suiza. 
Se prohíbe su reproducción total o parcial por cualquier medio, incluido electrónico, sin permiso previo y por escrito de los editores. 


\section{LA DICTADURA \\ DE LA CONCIENCIA*}

Libero al hombre de la opresión de un espíritu

que se ha convertido en su propia finalidad, de autocastigos

sórdidos y humillantes, de una quimera llamada conciencia y moral,

$y$ de las reivindicaciones de una libertad y de una autonomía personal

de las que solo una ínfima minoría puede ser capaz. ${ }^{l}$

La conciencia [tomando las verdades morales universales como referentes]

es una invención judaica; es como la circuncisión, una mutilación del hombre.

[...] No hay verdad, ni en el sentido moral ni en el sentido cientifico. ${ }^{2}$

\section{Hermann Rauschning, presidente del}

Senado de Danzig de 1933 a 1934, comunicó así ciertas ideas de Adolf Hitler, quien afirmaba que el "nuevo hombre" que el partido nazi quería ver surgir tenía la obligación de liberarse de la opresión de su conciencia moral y de un espíritu autónomo sometiéndolos a los del Führer. Solo estos últimos representarían la conciencia de los alemanes, la que a su vez, dictaría los valores morales que debían seguirse. Así, Hitler

* Traducción de Magdalena Romero.

${ }^{1}$ Hermann Rauschning, Gespräche mit Hitler, 1940, Nueva York, Europa, p. 212. Respecto al tema de la autenticidad de sus confidencias, véase Theodor Schieder, Hermann Rauschnings Gespräche mit Hitler als Geschichtsquelle, 1972, Opladen, Westdeutscher Verlag. Que estas palabras sean exactamente las que pronunció el Führer o no, en nada cambian la tesis de este trabajo.

${ }^{2}$ Ibid., p. 210. 
encarnaría, según la expresión de Hannah Arendt, "la ley del país". 3 A esta liberación hizo referencia explícitamente Hermann Göring, iy con qué fuerza!, cuando declaró: "¡No tengo ninguna conciencia! Mi conciencia se llama Adolf Hitler". ${ }^{4}$ Si Hermann Göring exigía que se pusiera en práctica la solución final en contra de los judíos, no fue el único que sometió su conciencia a las exigencias de Adolf Hitler. Este último estaba rodeado por numerosos simpatizantes que no eran "criminales, monstruos ni violadores sádicos", sino que — precisa Arendt— se encontraban entre "los miembros más respetados de la sociedad respetable". ${ }^{5}$ Lo mismo sucedió con Adolf Eichmann, que, así como hizo aplicar el plan aprobado en la conferencia de Wannsee organizando la deportación de judíos a los campos de concentración, puede ser contado entre los nombres de las personas "ordinarias". Luego se defendió ante el tribunal de Jerusalén — que lo condenó a ser colgado el $1^{\circ}$ de junio de 1962 - argumentando que no había hecho otra cosa más que obedecer a su conciencia, que le dictaba seguir el imperioso principio consistente en conformar sus actos de tal manera que, si el Führer se enteraba, no pudiera sino aprobarlos. De tal suerte, había escogido subyugar - en un impulso que era tanto un acto de fe como un proceso de renuncia a la responsabilidad — su juicio personal al del Führer, figura 10 simbólica de la ley de su país. En otras palabras, había sometido deliberadamente su conciencia - al igual que Hermann Göring — a la de Adolf Hitler; mientras que esta negaba todo valor a una verdad moral universal so pretexto de que una moral tal constituiría "una mutilación del hombre". El abogado de Adolf Eichmann ilustra de maravilla esta tesis cuando calificó los sucesos de Auschwitz como un "caso médico". Dicho de otra manera, la ética no sería en definitiva más que una cuestión de costumbres,

${ }^{3}$ Hannah Arendt, Responsability and judgment, 2003, Nueva York, Schocken Books, p. 43.

${ }^{4}$ Rauschning, Gespräche mit Hitler, p. 77. Rauschning comunica las palabras del Führer tras un encuentro al inicio del verano de 1934. "Por tanto, exijo de ustedes, ante todo, una obediencia ciega. No está en ustedes determinar lo que se debe hacer en su área de acción. Ni podré yo comunicarles siempre los detalles de mis intenciones. Su obediencia debe surgir de su confianza en mí." Ibid., p. 136.

${ }^{5}$ Arendt, Responsability and judgment, pp. 42-43. Véanse los estudios históricos de Christopher Browning, Ordinary men: Reserve Police Battalion 101 and the final solution in Poland, 1992, Nueva York, Harper Collins. Para un tratamiento literario, véase Jonathan Littell, Les bienveillantes, 2006, París, Gallimard. 
subordinadas a la historia y a la cultura. Dicho jurista pretende, de esta manera, descalificar la acusación según la cual su cliente estaría en el error a nivel de la conciencia y, partiendo de ahí, sería culpable. Arendt aporta a ese tema una precisión:

Lo que se produjo en Auschwitz y en otros campos de concentración era un "caso médico". Todo pasó como si la moral, en el momento mismo de su total derrumbe en el seno de una vieja nación sumamente civilizada, se revelara en el sentido original de la palabra como un conjunto de hábitos, de usos y costumbres, que uno podía intercambiar por otro conjunto sin que eso causara más dificultades que las de cambiar los modales en la mesa de todo un pueblo. ${ }^{6}$

Un buen número de contemporáneos considerarían, siguiendo a Arendt, que la postura del abogado era "increíble". ${ }^{7}$ Esta incredulidad tiene su origen en el presupuesto según el cual existen, a un tiempo, acciones morales intrínsecamente malas, que no caen en simples cuestiones de usos y costumbres, y una conciencia moral que nos prohíbe cometerlas. Parecería, según esto último, legítimo condenar a Adolf Eichmann — quien estaba, él también, dotado de una conciencia, aun si no hizo uso personal inmediato de ella, puesto que la subordinó a la de alguien más - al igual que parecería legítimo, por analogía, condenar a toda persona que haya cometido acciones morales malas en sí, a nivel universal.

¿Adoptar tal perspectiva no supondría legitimar siempre, como afirma Ruwen Ogien, una postura "paternalista", que dictaría - independientemente del sujeto, de su historia y cultura - aquello que convendría hacer desde un punto de vista moral, y que se opondría en definitiva — según este filósofo francés - a "la libertad de conciencia"? ${ }^{8}$ ¿La exigencia de someter la propia conciencia a una verdad moral trascendente, suscep-

${ }^{6}$ Arendt, Responsability and judgment, p. 43.

${ }^{7}$ Loc. cit.

${ }^{8}$ Ruwen Ogien, La Morale a-t-elle un avenir?, 2006, Nantes, Éditions Pleins Feux, p. 54. "Es en el nombre de la 'dignidad humana' — que debe comprenderse en ese contexto como una "realidad trascendente" (p. 54), que no requiere la libre sumisión del sujeto- que se desafió el derecho a elegir libremente el tipo de vida que uno desea llevar, aquello que uno quiere hacer de su vida y de su cuerpo (derecho que incluye el de abortar, por ejemplo). Se trata de una noción que sirve para justificar intervenciones paternalistas", p. 55. 
tible de ser identificada — al menos en parte- por medio de la razón filosófica, no sería análogamente similar a la exigencia de someterse a lo que Adolf Hitler hubiera definido subjetivamente como moralmente bueno? Con la finalidad de liberarse de cierta manera de un totalitarismo de esta especie, o por analogía, del paternalismo considerado por Ruwen Ogien como totalitario, ¿no debería uno, en última instancia, dirigirse antes de actuar a nada más que a lo que dicta la conciencia moral subjetiva y autónoma? Esta postura parece, a primera vista, postular la primacía de la conciencia personal que John Henry Newman defendió admirablemente al hacer su célebre brindis por su propia conciencia en la carta que escribió al duque de Norfolk: "Caso de verme obligado a hablar de religión en un brindis de sobremesa [...] beberé por el papa con mucho gusto; pero primero por la conciencia, y luego por el papa". ${ }^{9}$ El teólogo alemán Joseph Ratzinger, un siglo más tarde, confirmó esta postura precisando que seguir siempre la propia conciencia es un deber moral: "Nadie tiene el derecho de actuar de manera contraria a su conciencia [...] Nunca es un error seguir una convicción adquirida; incluso, es un deber". ${ }^{10}$

Seguir en toda circunstancia la conciencia personal como expresión de la autonomía del sujeto y no delegar el propio discernimiento a persona alguna es una exigencia frecuentemente concebida desde el término de la Segunda Guerra Mundial como capaz de servir de baluarte en contra de toda forma de totalitarismo. Contrariamente a lo que afirmaba Adolf Hitler, a saber, que "una ínfima minoría puede ser capaz"11 de ejercer su autonomía, postulamos de aquí en adelante que todos y cada uno de nosotros tenemos esta capacidad. ${ }^{12}$ Sin embargo, en estos últimos años se ha radicalizado el llamado a la autonomía del sujeto con el objetivo de contrarrestar el totalitarismo, lo que ha dado lugar a una concepción de la conciencia personal que puede ser calificada de posmoderna y que tiene por objeto una conciencia que se presenta como único fundamento de los actos morales.

${ }^{9}$ John Henry Newman, Carta al duque de Norfolk, 1996, Madrid, Rialp, trad. de Víctor García Ruiz, p. 82.

${ }^{10}$ Joseph Ratzinger, “Conscience et vérité”, Communio, 21/1 (1996) (21), pp. 111-112.

${ }^{11}$ Hermann Rauschning, Gespräche mit Hitler, p. 212.

${ }^{12}$ Véase Isaiah Berlin, Four essays on liberty, 1969, Oxford, Oxford University Press, pp. 118-172. 


\section{La conciencia posmoderna}

\section{El llamado a la autonomía}

La concepción de la conciencia personal a la que se refiere Ruwen Ogien pone en el seno de la comunidad de sujetos, en primer término, la importancia del respeto a la subjetividad al momento de tomar decisiones morales. Al mismo tiempo, esta concepción pretende que la conciencia subjetiva sea indiscutiblemente la única instancia ética. En otras palabras, el contenido moral al que se somete la conciencia tiene su origen en la propia subjetividad o, eventualmente, en la comunidad de personas morales a la que el sujeto libremente decide pertenecer. Una concepción tal de la conciencia presupone una libertad comprendida, a la vez, como absoluta y como plenamente indeterminada, de tipo sartreana, que moldea la esencia humana (como lo expone la célebre afirmación del filósofo francés: la existencia precede la esencia); no solo no existe una naturaleza humana predeterminada y universal, sino que los valores no tienen justificación salvo en la libertad misma del sujeto, dado que no hay un cielo inteligible del que emanen. Los valores universales surgen de la quimera. El sujeto es su propio legislador; él inventa su propia ley.

¿Cuáles son las consecuencias? Entregado a sí mismo, el sujeto no sabe ya, en cuanto a su actuar moral, hacia qué orientarse; su libertad "se angustia" ante el hecho de que es "el fundamento sin fundamento de los valores". Jean-Paul Sartre declara que

mi libertad es el único fundamento de los valores y nada, absolutamente nada, justifica que adopte tal o cual valor, tal o cual escala de valores. [...] Y mi libertad se angustia de ser el fundamento sin fundamento de los valores. [...] no tengo recurso ni puedo recurrir a ningún valor por el hecho de que soy yo quien mantiene la existencia de los valores [...] tengo que hallar el sentido del mundo y de mi esencia: yo lo decido, solo, injustificable y sin excusa. ${ }^{13}$

${ }^{13}$ Jean-Paul Sartre, L'Être et le néant. Essai d'ontologie phénoménologique, 1943, París, Gallimard, pp. 76-77. 
El filósofo francés niega la existencia de los actos morales intrínsecamente malos o buenos. El carácter moral del acto personal se revela en la libertad del sujeto responsable y sincero con los valores que escoge para sí. La libertad como autodeterminación radical es la única norma de la acción moral. El sujeto podría, por lo tanto, no solamente quererlo todo, sino también hacerlo todo dentro de la mesura según la cual asuma la responsabilidad de sus actos. El contenido de la conciencia moral ya no se debe buscar en una alteridad objetiva que dicte el actuar moral, sino en el sujeto mismo. Una libertad tal se desvincula de los horizontes de significado, como lo recalca Charles Taylor, ${ }^{14}$ poniéndose ella misma en el origen del sentido.

Esta idea de libertad es confundida por ciertos filósofos contemporáneos con el principio de autonomía, pero este último posee significados en parte distintos del concepto postulado en el siglo XVIII por Emmanuel Kant. Para algunos, como Lawrence Kohlberg, es señal de madurez psicológica. Para otros, designa un derecho fundamental de la persona en el sentido de que el sujeto autónomo es el amo de su existencia sin someterse a una injerencia extrínseca. Para otros, finalmente, significa una autonomía absoluta de la libertad, que decide sobre el contenido moral de las acciones personales, aparte de la razón, que no es 14 ya la que funda universalmente las reglas morales. En ese sentido particular, cada vez más filósofos, sobre todo en el marco del debate bioético, comprenden la noción de autonomía que niega toda autoridad moral extrínseca al sujeto.

Por tanto, una persona puede decidir de manera autónoma someterse a un experimento que lleve a su deceso, o a un atentado profundo en contra de su personalidad o a matarse con la ayuda de otros en un acto de suicidio asistido o eutanasia. Se esgrime el mismo argumento para las personas que en el pasado ejercieron una autonomía y que, por razones particulares, ya no son ni serán capaces de hacerlo, así como para las personas que no son aún autónomas o que no serán jamás capaces de ejercer su autonomía. En estos casos particulares, la autonomía se transfiere a personas autónomas, como los miembros de la familia

${ }^{14}$ Cfr. Charles Taylor, The sources of the self. The making of the modern identity, 1989, Cambridge, Harvard University Press. 
cercana, que son responsables de quienes no pueden serlo. A estas personas autónomas les incumbe la elección de legitimar o no una eventual experimentación, como los estudios realizados en nuestros días con embriones humanos excedentes, destinados a la fecundación in vitro con fines de reproducción o investigación. La legitimidad de la experimentación sobre embriones humanos debería aplicarse igualmente — siguiendo esta lógica - a todos los demás casos en los que un ser humano esté privado del ejercicio de su autonomía. Pensémoslo para el neonato, para el individuo con discapacidad intelectual profunda, para el demente... No obstante, la mayoría de las personas se rehúsa a legitimar la experimentación en estos últimos tres casos, arguyendo, mediante un apoyo notorio en la noción de la persona social, que existe, paradójicamente, una dignidad de la persona que escapa a la elección autónoma del sujeto. Esto significaría que la conciencia moral no sería la única instancia ética, sino que debería someterse a unos valores universales fundados racionalmente, sobre todo en lo que concierne a la dignidad humana.

A pesar de esta referencia común a la noción de dignidad de la persona humana, por medio de la cual se le reconocen derechos — sobre todo, el derecho a la vida-, ciertos autores contemporáneos se rehúsan a apelar a estos derechos como parte del concepto de dignidad que ellos califican de "tonto" y de "inútil", prefiriendo el término de autonomía entendido en el sentido ya indicado de libertad absoluta. "La dignidad es - precisa Steven Pinker - una noción difusa y subjetiva, que no pesa nada en contraposición con las exigencias morales que se le asignan". ${ }^{15}$ Peter Singer subraya que la dignidad de todo ser humano no constituye más que una "bella expresión blandida por aquellos que están cortos de argumentos". ${ }^{16}$ Ruth Macklin propone, por su parte, desterrar el término de la bioética, so pretexto de que sería tautológico. No expresaría nada aparte del respeto a la autonomía de las personas. "La dignidad es un concepto desprovisto de sentido en el plano de la

${ }^{15}$ Steven Pinker, "The stupidity of dignity", The New Republic, 28 de mayo de 2008.

${ }^{16}$ Peter Singer, "All animals are equal", en Peter Singer (comp.), Applied ethics, 1986, Oxford, Oxford University Press, p. 228: "Philosophers frequently introduce ideas of dignity, respect, and worth at the point at which other reasons appear to be lacking, but this is hardly good enough. Fine phrases are the last resource of those who have run out of arguments." 
ética médica; puede ser eliminado sin que el contenido de esta se vea afectado". ${ }^{17}$

Visto lo anterior más de cerca, la razón que expone Ruth Macklin para eliminar el término "dignidad" revela más bien un cambio en el significado del contenido de esta noción. Macklin propone llevar a cabo un desplazamiento en el interior del discurso deslizando dicho significado del respeto de la persona - fundado con independencia del libre albedrío - hacia un respeto de la autonomía absoluta del sujeto. Esta última, entendida como una libertad que no es sometida a restricción alguna, en oposición a las "seudo" leyes morales universales que tendrían su origen, ya fuera en un cielo inteligible platónico, ya en una razón universal. La autonomía kantiana vendría a restringir la autonomía sartreana del sujeto, pues esta última no podría ejercerse más que en los límites de la dignidad humana. Por tanto, la autonomía no sería absoluta en sí, lo que implicaría igualmente que la dignidad sería superior de cierta manera. Esa transferencia de la noción de dignidad a la noción de autonomía es retomada por Ruwen Ogien, quien sostiene que el concepto de "dignidad humana" es una "expresión pomposa e intimidante", ${ }^{18}$ un concepto "inútil y peligroso", ${ }^{19}$ pues se "ha convertido, al contrario de su significado inicial, en un concepto puramente paternalista, que sirve para contender contra el derecho de los adultos a disponer libremente de su vida y de su cuerpo". ${ }^{20}$ La dignidad humana entendida como realidad trascendente, en la medida en la que no depende de una libertad cualquiera del sujeto llamado a conformarse, se opone al derecho a "la libertad de conciencia". ${ }^{21}$

\section{La ética secular}

Entender la conciencia subjetiva como la única instancia ética reposa igualmente sobre la afirmación de que la razón humana no está en

${ }^{17}$ Ruth Macklin, "Dignity is a useless concept", British Medical Journal, 327 (2003), pp. 1419-1420.

${ }^{18}$ Ogien, La Morale a-t-elle un avenir?, p. 16.

${ }^{19}$ Ogien, La vie, la mort, l'État. Le débat bioéthique, 2009, París, Grasset, p. 87.

${ }^{20}$ Ogien, La Morale a-t-elle un avenir?, pp. 15 y 55.

${ }^{21}$ Ibid., p. 54. 
capacidad de fundar un discurso moral universal. Aunque se sostenga que se conforma a una objetividad en el plano de la utilidad y de la experimentación, se le niega no obstante esta capacidad en el plano ético y político, que estructuran, propiamente hablando, el nivel existencial personal. Tristram Engelhardt subraya que hace falta, por tanto, contentarse con una ética secular, formalista y procesal que desecha la idea de verdad ética y que pone, en su lugar, un marco general sin contenido moral, formado en torno a los principios de consentimiento, tolerancia, permisividad y benevolencia con respecto a las éticas particulares. ${ }^{22}$ Cada sujeto, así como cada comunidad de sujetos, vive según sus propios principios éticos sin tratar de imponer su punto de vista. Semejante ética secular es necesariamente — precisa el filósofo estadounidense - permisiva.

[L]a paz perpetua, exenta de represión, sucederá probablemente, pero a condición de que convengamos en aprobar las elecciones que las personas hacen respecto a lo que les pertenece, a sus recursos personales, en acuerdo con otras personas que aprueban esa elección, así como en acuerdo con sus comunidades, tan desviadas como sean, e igualmente si sus elecciones son profundamente ofensivas. ${ }^{23}$

La ética secular pretendería, según Michel Onfray, que todo fuera facultativo; cada quien sería libre de decidir y definir sus responsabilidades a voluntad.

En el campo de esas nuevas posibilidades nada es obligatorio y todo facultativo... La posibilidad de abortar no coarta ni obliga a nadie, como tampoco la de recurrir a la clonación o a la eutanasia. Argumentar las posibilidades no fuerza a nadie a efectuar una elección que ataque su moral. ${ }^{24}$

${ }^{22}$ Cfr. Tristram Engelhardt, The foundations of bioethics, 1996, Oxford, Oxford University Press.

${ }^{23} \mathrm{Ibid}$., p. 15: "Perpetual peace in the absence of repression will likely come, if ever, when we are willing to endure the choices persons make with themselves, their private resources, consenting others, and in their communities however deviant, even when those choices are profoundly wrong".

${ }^{24}$ Michel Onfray, Féeries anatomiques. Généalogie du corps faustien, 2003, París, Grasset, pp. 82 y 96 s. 
Esta ética implica la imposibilidad a priori de establecer racionalmente una jerarquía entre las diferentes concepciones del bien, que surgen únicamente de la esfera subjetiva, o incluso intersubjetiva. Uno no podría resolver un desacuerdo mediante argumentos racionales. ${ }^{25}$ En la medida en que una persona hubiera decidido libremente llevar a cabo una acción moral, uno no podría adoptar una postura respecto a esa elección, o sea, emitir un juicio de valor, sin ser calificado de paternalista e intolerante. Por consiguiente, esta posición revela algunos problemas, notablemente, el de cierta inadecuación. En efecto, si la razón filosófica fuera verdaderamente capaz de encontrar la exigencia de tal ética secular - consistente en un marco general desprovisto de contenido moral y acompañada de una definición performativa de la persona que se concretara por el ejercicio de la conciencia personal y de la acción moral— ${ }^{26}$ debería también ser capaz, en principio, de fundar la definición analítica de una acción moral, a saber, la que consiste en alcanzar lo verdadero mediante una vida buena. Nos encontramos ante una petición de principio que niega a priori que la razón filosófica pueda asentar el discurso ético.

La referencia al concepto de la dignidad de la persona humana que presupusiera una naturaleza humana independiente de la libertad, así como la posibilidad de un discurso filosófico ético universal, volvería a "renegar, en su principio, el núcleo de los derechos del hombre desde el punto de vista del pensamiento político moderno, es decir, a enfrentarse radicalmente a la libertad del individuo en la relación que tiene consigo

25 "Hay verdaderas diferencias en cuanto a las percepciones morales, las cuales sustentan interpretaciones de la bioética que son sustancialmente diferentes unas de las otras. Esas diferencias surgen de la disponibilidad de premisas y postulados diversos que sirven como evidencia a los participantes en una controversia moral, de manera que las disputas no se pueden resolver ni por medio de un argumento sensato, razonable ni apelando a una autoridad moral reconocida por todos [...]. Solo una moral general, secular y carente de contenido puede cruzar tales abismos y permitir una colaboración en ausencia de una competencia moral cargada de contenido." Engelhardt, The foundations of bioethics, p. 81.

${ }^{26}$ Véase Bernard N. Schumacher, "Tout être humain est-il une personne? Controverse autour de la définition de la personne dans la discussion éthique médicale contemporaine", Laval Théologique et Philosophique, 61/1 (2005), pp. 107-134, y "La personne comme conscience de soi performante au cœur du débat bioéthique. Analyse critique de la position de John Locke", Laval Théologique et Philosophique, 64/3 (2008), pp. 709-743. 
mismo". ${ }^{27}$ Se puede encontrar una afirmación similar en la crítica de Mylène Botbol-Baum a la posición adoptada por Jürgen Habermas, quien se opone a una eugenesia liberal, ${ }^{28}$ pues transformaría radicalmente la naturaleza humana. El filósofo alemán se refiere a la existencia de una naturaleza humana del embrión, que él designa como una vida humana "antepersonal" 29 o una "segunda persona" 30 en el nombre de un acto de "socialización por anticipación", ${ }^{31}$ es decir, de un acto de anticipación respecto a aquello que será: una persona. Sin embargo, según Habermas tal vida humana posee cierta dignidad que identifica no con la dignidad de la persona, sino con la de los cadáveres humanos. Así, denuncia "una sumisión del cuerpo viviente y de la vida a la biotecnología", ${ }^{32}$ y al hacerlo se afilia — según Botbol-Baum — a

perspectivas neoheideggerianas, que intentan reencontrar la esencia del ser humano en un rechazo tecnofóbico respecto a todo lo tocante a la naturaleza sexual del humano. Esta postura lo encasilla en un moralismo difícilmente distinguible de una postura autoritaria y neoconservadora que, en términos del derecho de gentes, puede volverse anticonstitucional. [...] Hay una naturalización de la moral en el concepto de especie humana. ${ }^{33}$

${ }^{27}$ Olivier Cayla y Yan Thomas, Du droit de ne pas naître. À propos de l'affaire Perruche, 2002, París, Gallimard, p. 13. Se encuentra una idea parecida en Claude Sureau, inventor del monitor electrónico del corazón fetal, quien sostiene que uno "tampoco puede aceptar el uso de restricciones legales para imponer unas convicciones a aquellos que no las comparten"; Claude Sureau, Son nom est personne. Avant de naître, l'enfant est-il une chose, un amas de cellules ou un patient?, 2005, París, Albin Michel, p. 29.

${ }^{28}$ Véase Jürgen Habermas, Die Zukunft der menschlichen Natur. Auf dem Weg zu einer liberalen Eugenik?, 2001, Fráncfort del Meno, Suhrkamp.

${ }^{29}$ Ibid., p. 72.

${ }^{30}$ Ibid., p. 120.

${ }^{31}$ Ibid., p. 66.

${ }^{32}$ Habermas, citado en Henry Atlan y Mylène Botbol-Baum, Des embryons et des hommes, 2007, París, Presses Universitaires de France, p. 73.

${ }^{33}$ Ibid., pp. 73-74. La autora continúa diciendo que "después de Rousseau, la libertad del hombre se quiere neutra; ya no está ligada a la capacidad de someterse a una ley inscrita en la naturaleza, sino a su perfectibilidad, a su capacidad de desarrollar un mundo moral fuera de la naturaleza, lo que ha conducido [...] a la negativa a identificar a la humanidad moral y a la especie humana", p. 75. 
En la medida en que un Estado democrático prescriba una sola teoría particular del bien en detrimento de las demás concepciones — partiendo del supuesto de que las diferentes concepciones del bien se definen, según Ruwen Ogien, como "moralmente indiferentes"_, ${ }^{34}$ estaríamos en presencia de la situación que Tristram Engelhardt describió como "de los preilustrados, que dispusieron de poderes inquisitoriales para regir la vida privada de los ciudadanos". ${ }^{35}$ Engelhardt describe a quienes imponen su punto de vista en un Estado democrático y en el marco de una ética secular como "fanáticos moralistas", "ideólogos" o "fascistas". ${ }^{36}$ Vale la pena precisar que el filósofo piensa que tales personas forzarían a las demás a adoptar cierta concepción del bien sin su consentimiento y, si hiciera falta, apoyándose en la fuerza del Estado e incluso, podría uno añadir, en la manipulación manifiesta o encubierta.

Para un posmoderno como Tristram Engelhardt, no existe ningún criterio racional que trascienda a la subjetividad y que permita afirmar que cierta concepción del bien subjetivo o intersubjetivo es mejor que otra. Asimismo, repite la afirmación de Richard Rorty, quien defiende - fundado en una antropología que niega la existencia de una naturaleza humana y que define al ser humano como un "animal flexible, proteiforme, autocreador" - ${ }^{37}$ un "relativismo cultural" "asociado al irracionalismo, porque rechaza la existencia de hechos transculturales moralmente pertinentes", ${ }^{38}$ entre los que se encuentran los derechos del hombre. No existe ninguna verdad o racionalidad ahistórica; ${ }^{39}$ no existe, entonces, ningún criterio que permita denunciar un pensamiento como irracional. André Compte-Sponville expresa admirablemente esta postura cuando, rechazando la posibilidad de fundar una moral universal con ayuda de la razón, se opone al fascismo y al racismo sencilla-

${ }^{34}$ Ruwen Ogien, La panique morale, 2004, París, Grasset, p. 28.

${ }^{35}$ Tristram Engelhardt, "Introduction”, en William B. Dondeson, H. Tristram Engelhardt y Stuart F. Spicker (comps.), Abortion and the status of the fetus, 1983, Dordrecht, Reidel, p. XIX.

${ }^{36}$ Engelhardt, The foundations of bioethics, p. 81.

${ }^{37}$ Richard Rorty, "Human rights, rationality, and sentimentality", en Truth and progress. Philosophical papers, vol. 3, 1998, Cambridge, Cambridge University Press, p. 170.

${ }^{38}$ Ibid., p. 171.

${ }^{39}$ Ibid., p. 176. 
mente porque no los quiere, es decir, por una mera preferencia subjetiva: "El fascismo, el racismo [...], aquello me repugna, y si lucho en su contra, no es porque una 'verdad' los condene objetivamente [...], sino, simplemente, porque no los quiero". ${ }^{40}$

Una toma de postura que afirmara que ciertas acciones son intrínsecamente malas sería, desde su punto de vista, un ataque inadmisible contra la libertad de pensamiento y de acción de los otros. Percibida como un intento por forzar a los demás a adoptar un punto de vista específico, iría en contra de la misma dignidad de la persona, entendida como autonomía absoluta. Esta postura quedaría estigmatizada como una actitud que hemos asimilado a la de "intolerancia", incluso, a la de "antidemocracia", ${ }^{41}$ ejemplificada por el fragmento citado arriba de BotbolBaum, o nuevamente, a la de "arrogancia", ${ }^{42}$ vuelta incapaz de todo diálogo. Compte-Sponville afirma, mezclando "Platón, Stalin, Juan Pablo II", que "el dogmatismo práctico, que concibe el valor como una verdad, da como resultado, así, la buena conciencia, la autosuficiencia, el rechazo o el menosprecio del otro, es decir, la intolerancia". ${ }^{43}$

${ }^{40}$ André Comte-Sponville, "Le bon, la brute et le militant", en Lettre Internationale, 11 (1986-1987), reimpreso en Une éducation philosophique, 1989, París, Presses Universitaires de France, p. 140. "A lo que asistimos en este fin de siglo no es de ninguna manera al final de la moral, sino a la desaparición de todos sus fundamentos, es decir, de toda legitimación objetiva. Cada quien sabe, solitariamente, lo que juzga bueno y, en consecuencia, lo que debe hacer. Pero ya nadie tiene los medios para hacer de eso una moral universal (que valiera imperativamente para todos), porque nada tiene ya un fundamento absoluto, si no para proponer (eso lo encuentra uno siempre), por lo menos para demostrar", p. 140.

${ }^{41}$ Joseph Ratzinger, Wahrheit, Werte, Macht. Prüfsteine der pluralistischen Gesellschaft, 1993. Friburgo, Herder, pp. 67-68.

42 "En nuestros días, se ha convertido en un lema con una fuerza irresistible, etiquetar como ingenuos y arrogantes a aquellos que uno acusa de que creen poseer la verdad. Tales personas, parece, son incapaces de dialogar y no se les debe tomar en serio." Joseph Ratzinger, Unterwegs zu Jesus Christus, 2004, Augsburgo, Sankt Ulrich, p. 69. Véase también Glaube, Wahrheit, Toleranz, 2005, Herder, Friburgo, p. 95: "El relativismo aparece como el escaño filosófico de la democracia: nadie podría pretender conocer el camino correcto. [...] Un sistema que exaltara la libertad debería, conforme a su esencia, ser un sistema de posiciones relativas, concordantes entre ellas, dependientes de constelaciones históricas y abiertas a nuevos desarrollos. Una sociedad libre sería una sociedad relativista; solamente a partir de ese requisito podría mantenerse libre y abierta al devenir." "El relativismo posmoderno "se ha convertido en un problema central para la fe". Ibid., p. 94.

${ }^{43}$ André Comte-Sponville, Petit traité des grandes vertus, 1995, París, Presses Universitaires de France, p. 251. 
Y más adelante precisa que "el dogmatismo práctico conduce siempre, aunque sea en forma atenuada, a la intolerancia. Si los valores son verdaderos, si son conocidos, uno no podría discutirlos ni escogerlos, y quienes no compartan los nuestros estarían equivocados". ${ }^{44}$

\section{La dictadura de la intolerancia en nombre de la libertad}

La afirmación del relativismo moral según la cual todos los valores son válidos y que descansa en la autonomía absoluta del sujeto — a saber, que la conciencia subjetiva es la única instancia ética - conduce a la imposibilidad de afirmar que una conciencia moral puede ser errónea en sí desde un punto de vista transcultural y transhistórico. Uno no podría condenar una conciencia autónoma más que refiriéndose a la inautenticidad y a la insinceridad — la mala fe — respecto a los valores que ha elegido libremente y también respecto a los de una comunidad intersubjetiva que el sujeto comparte. Por lo tanto, ¿habría sido posible condenar a Adolf Eichmann? Suponiendo que haya seguido sinceramente, así como lo exige John Henry Newman, lo que su conciencia le dictaba hacer - incluso si se trataba, en ese caso, de someterla a la de Adolf Hitler-, su condena no podría ser justificada, al menos si nos colocamos en el punto de vista de la tesis subyacente a la conciencia posmoderna. Su condena sería el signo de la toma de poder por parte de cierta concepción moral (la que lo condena) sobre otra (la de Adolf Eichmann). La superioridad de la primera concepción no podría ser demostrada por la razón, la cual ha abdicado, sino únicamente por la fuerza. El discurso racional universal daría lugar a ley del más fuerte y a la arbitrariedad. De esto resultaría que la condena de Adolf Eichmann sería un acto totalitario que negaría el principio mismo de tolerancia respecto a la tesis de la inviolabilidad de la conciencia moral subjetiva. La actitud de una comunidad particular al respecto de Adolf Eichmann - aquella que lo condena - sería similar a la de la comunidad del nazismo hacia los débiles. Estaríamos bajo el control de una nueva ideología que sería,

${ }^{44}$ Ibid., p. 253. 
desde cierto punto de vista, similar a la que se sometió voluntariamente Adolf Eichmann.

Se sigue de esta lógica que la exigencia, a partir del término de la Segunda Guerra Mundial, de seguir legítimamente la conciencia moral como defensa contra el surgimiento de un nuevo totalitarismo - comúnmente comparado con el nazismo, para el cual la conciencia es una quimera - resultó ser el nido mismo del totalitarismo, en la medida en que la conciencia fue comprendida décadas más tarde como el único criterio ético. En efecto, la conciencia moral posmoderna aparece bajo "el manto protector de la subjetividad", ${ }^{45}$ descrito como "un eufemismo que se traduce en la inexistencia de una conciencia verdadera, es decir, de un reconocimiento común de la verdad. Cada quien determina por sí mismo su norma y, en el relativismo general, nadie puede ayudar al otro ni mucho menos hacerlo progresar". ${ }^{46}$

Semejante conciencia es equiparable a la de Adolf Eichmann en cuanto a su rechazo a un eventual cuestionamiento a la luz de la razón. Mientras que la primera rechaza un diálogo auténtico a la luz de la razón crítica y dialógica, la segunda delega a otro por comodidad, conformismo o pereza, como ya lo subraya Emmanuel Kant en su célebre ¿Qué es la Ilustración?, el juicio racional relativo al contenido moral. La conciencia posmoderna, observa Joseph Ratzinger,

puede justificar su incapacidad obstinada de autocorrección por medio de la fidelidad a una voz interior. La conciencia deviene, por tanto, en el principio de una terquedad subjetiva propuesta como absoluta, justo como, en el otro caso [el nazismo], devino en el principio de servidumbre del yo para con un "nosotros" impersonal o un yo extranjero. ${ }^{47}$

${ }^{45}$ Ratzinger, Wahrheit, Werte, Macht, p. 33.

${ }^{46}$ Ibid., p. 46. "La conciencia subjetiva deviene, en definitiva, la única instancia ética." Benedicto XVI, Glaube und Vernunft. Die Regensburger Vorlesung, 2006, Friburgo, Herder, p. 27.

${ }^{47}$ Joseph Ratzinger, Kirche, Ökumene und Politik, 1987, Einsiedeln, Johannes Verlag, p. 156. Eberhard Schockenhoff subraya que "sin la orientación vinculante de los principios éticos y las normas morales, la conciencia se rebaja a una demostración patética de la arbitrariedad subjetiva. La autoafirmación, que se impone al amparo de la libertad de conciencia democrática, ya no conduce a la confrontación con la pretensión de la verdad moral; sirve, por el contrario, para la legitimación de proyectos de acción individuales y se rebela contra la crítica 
La tesis de la conciencia moral que recae únicamente sobre los intereses y las preferencias del sujeto autónomo, negando la posibilidad de un discurso racional sobre la verdad moral, incluso parcial, pasa a ser - precisa Joseph Ratzinger_- "la verdadera premisa de la sumisión y la dominación totalitaria". ${ }^{48}$

Una sociedad que, de cierta forma, se "liberara" de una moral universal racional resguardándose bajo el manto de lo que Joseph Ratzinger presenta como la "dictadura de una tolerancia", 49 a saber, la dominación ideológica de la opinión según la cual todo se vale, como lo desarrolla Philippe Bénéton ${ }^{50}$ — y como lo ilustran las propuestas de algunos filósofos citados arriba-, tendería irónicamente hacia lo que se ha llamado una "perfecta tiranía"51 o un "totalitarismo caracterizado". ${ }^{52}$ Joseph Ratzinger llega a sostener incluso que la tentación de llevar a cabo una sociedad tal "presenta una aterradora similitud, e incluso es idéntica a

moral venida de fuera. [...] La referencia a la conciencia personal sirve antes bien para protegerse, para defenderse contra las dudas y la vanidad ligada a situaciones temporales. Postula el derecho de hacer de los intereses personales el punto de partida de la resolución de conflictos morales. [...] Quien descansa en su conciencia parece estar dispensado de la restricción que consiste en justificar su acción.” Wie gewiss ist das Gewissen? Eine ethische Orientierung, 2003, Friburgo, Herder, pp. 55-56.

${ }^{48}$ Ratzinger, Kirche, Ökumene und Politik, p. 153.

49 "Pienso que uno puede llegar a una situación en la que la tolerancia deba organizarse, en oposición a la dictadura de una tolerancia que no es más que aparente y que desencadena el escándalo de la fe [que afirma sostener la verdad] declarándola intolerante. Aquí aparece verdaderamente y a plena luz del día la intolerancia de los 'tolerantes'.” Joseph Ratzinger, Gott und die Welt. Die Geheimnisse des christlichen Glaubens. Ein Gespräch mit Peter Seewald, 2000, München, Deutsche Verlags-Anstalt, p. 390.

${ }^{50}$ Philippe Bénéton subraya que en "nombre del relativismo, se cierra el debate: el dogmatismo sigue. En gran medida, el principio de tolerancia, tal como se le entiende hoy, funciona como una censura: en el límite, quien habla de talento, sabiduría o virtud da prueba de intolerancia. El mecanismo es de doble filo. Por un lado (corriente relativista), tiende a neutralizar las distinciones intelectuales y morales tradicionales: tal conducta es un asunto privado; tal disciplina vale por las otras; tales culturas son iguales... Por el otro (corriente dogmática), dicho mecanismo establece prohibiciones: cualquiera que diga algo distinto carece de tolerancia o de igualdad. El proceso funciona como una máquina que dispara juicios autorizados y juicios no autorizados tras la apariencia de la libertad. La nueva moral avanza enmascarada". Philippe Bénéton, "L'homme démocratique et l'emprise de l'opinion", en François-Xavier Putallaz y Bernard N. Schumacher (comps.), L'humain et la personne, 2008, París, Cerf, 2008, pp. 406-407.

${ }^{51}$ Ratzinger, Kirche, Ökumene und Politik, p. 186. "Toda liberación de la moral no puede ser sino una liberación orientada hacia la tiranía.” Ibid., p. 194.

${ }^{52}$ Juan Pablo II, Evangelium vitae, 1995, núm. 20 y 30. 
la que, en apariencia, se encuentra detrás de nosotros [sobre todo, el régimen nazi], y eso a pesar de los cambios de nombres y colores". ${ }^{53}$

Tal sociedad se caracteriza por un rechazo al diálogo mayéutico socrático, el cual se distingue por un cuestionamiento desestabilizante a la luz de la razón argumentativa, que tiene como objetivo el conocimiento de "la verdad de las cosas". ${ }^{44}$ Sócrates da el nombre de misología ${ }^{55}$ a esta actitud de rechazo, a saber, el odio al pensamiento que André Glucksmann describe, refiriéndose explícitamente a los posmodernos, como una "eutanasia contemporánea de la razón” o "el suicidio de la razón socrática". ${ }^{56}$ Y mientras hoy la razón se desespera por alcanzar el verdadero conocimiento, incluso parcial, trascendiendo al sujeto o a la comunidad histórica y cultural de sujetos, se ve reducida a la expresión de un mundo particular o a la expresión cultural singular. De ahí se desprende que, en el plano ético, todo es cuestión de preferencias subjetivas o intersubjetivas, carente de moral, como lo subraya el abogado de Adolf Eichmann, o cuestión de modales de mesa, para retomar una expresión de Arendt.

Tanto en la dictadura nacionalsocialista, como en su réplica comunista, precisa Joseph Ratzinger, ya ninguna acción era percibida como intrínsecamente mala o inmoral. Todo lo que servía a los objetivos del movimiento o del partido estaba bien, cualquiera que fuera la inhumanidad de la acción. Asimismo, durante décadas se ha adoptado un proceso consistente en pisotear el sentido moral, lo que no podría sino conducir a un llano nihilismo, puesto que todos los objetivos anteriores han perdido su validez y la libertad ya no subsiste sino como la posibilidad de hacer lo que uno pueda en un instante, de volver interesante y cautivadora una vida que se ha quedado vacía. ${ }^{57}$

${ }^{53}$ Ratzinger, Kirche, Ökumene und Politik, p. 154.

${ }^{54}$ Véase Josef Pieper, "Wahrheit der Dinge”, en Werke, 1997, Hamburgo, Felix Meiner, vol. 5, pp. 99-179.

${ }^{55}$ Platón, Fedón 89d.

${ }^{56}$ André Glucksmann, "Le spectre de Typhon”, en Dieu sauve la raison, 2008, París, Desclée de Brower, pp. 99 y 101.

${ }^{57}$ Ratzinger, Wahrheit, Werte, Macht, p. 21. 
Al reducir las convicciones teórico-éticas del sujeto egológico, sordo a una alteridad radical, a las preferencias y a los intereses subjetivos e intersubjetivos, el hombre posmoderno se afilia a la tesis de la inexistencia de actos morales intrínsecamente malos e incluso, como recalca Glucksmann, a la tesis de "la relatividad del mal". ${ }^{58}$ Las conductas morales poseen un mismo valor en el marco de una ética secular. Se sustraen a una jerarquización independiente del sujeto y de una comunidad particular. "El sujeto trascendente, desprovisto de trascendencia - señala Jean François Mattéi-, no tiene otra salida que escapar en un relativismo generalizado"59 en el que todo se vale, en el que los absolutos se evaporan y en el que se les oscurece, como subraya Charles Taylor, "en el parloteo subjetivista sobre los valores". ${ }^{60}$ Esta crisis que el filósofo francés describe como La barbarie interior, ${ }^{61}$ "afecta la idea de verdad, en su necesidad teórica y, por consecuencia, la idea de una existencia humana dotada de sentido, en su exigencia práctica, pues ya no hay lugar para asignar una dirección a la humanidad fraccionada en comunidades irreductibles". ${ }^{62}$

De esto se desprende, como señala Glucksmann, que una "razón que renuncia a enunciar, renuncia a denunciar y cede ante lo arbi26 trario". ${ }^{63}$ De igual manera, subraya Eberhard Schockenhoff que "ahí donde toda búsqueda fragmentaria de la verdad entre personas cuyos puntos de vista divergen es reemplazada por la planificación social, desaparece el último fundamento de nuestro reconocimiento mutuo. ${ }^{64}$

${ }^{58}$ Glucksmann, "Le spectre de Typhon", p. 99.

${ }^{59}$ Jean-François Mattéi, La crise du sens, 2006, Nantes, Éditions Cécile Defaut, p. 43.

${ }^{60}$ Taylor, The sources of the self, p. 507.

${ }^{61}$ Cfr. Jean-François Mattéi, La barbarie intérieure. Essai sur l'immonde moderne, 1999, París, Presses Universitaires de France, 1999.

${ }^{62}$ Mattéi, La crise du sens, p. 105. Charles Taylor señala: “un subjetivismo total y perfectamente consecuente tiende hacia el vacío: ninguna realización tendría valor en un mundo donde literalmente nada tiene importancia más que la autorrealización". The sources of the self, p. 507.

${ }^{63}$ Glucksmann, "Le spectre de Typhon", p. 100.

${ }^{64}$ Schochenhoff, Wie gewiss ist das Gewissen?, p. 43. 


\title{
El fundamento de la conciencia moral
}

\author{
El elemento dialogal de la conciencia moral
}

La condena de actos morales cometidos por una persona que afirma haber seguido su conciencia no puede ser considerada como justa, y así escapar a la aleatoriedad, salvo si uno defiende, desde un principio, la posibilidad de un auténtico diálogo racional argumentativo que permita proponer un juicio en cuanto a la veracidad de los hechos. Ese diálogo no tiene por objetivo conocer — como lo habría dicho Tomás de Aquino- "aquello que los otros pensaron, sino aquello que tienen de verdad las cosas" ${ }^{65}$ En otras palabras: ¡No se preocupen por Sócrates! ${ }^{66}$ ni por el papa, si retornamos al brindis de John Henry Newman, sino primero que nada, por la verdad que esos pensadores expresan. ${ }^{67}$ Ahora bien, recurrir al logos filosófico no consiste en reducirlo a "un saber escolar que no concierne ya en nada a los hombres y que es incapaz de iluminar la realidad como un

${ }^{65}$ Josef Pieper, Noch wusste es niemand. Autobiographische Aufzeichnungen 1904-1945, en Werke, 2003, vol. complementario 2, p. 76. Pieper toma la última parte de su frase del comentario que Tomás de Aquino hace sobre el De caelo I, 22 de Aristóteles.

${ }^{66}$ Tal es la afirmación que hace Sócrates a Simias y Cebes en el Fedón, 91c. Véase Josef Pieper, Kümmert euch nicht um Sokrates! Drei Fernsehspiele, en Werke, 2002, vol. 1, pp. 1-131.

${ }^{67}$ El llamado urgente de Jospeh Ratzinger a regresar a la razón y, notablemente, a elegir el concepto de la razón, va dirigido a todos los fieles cristianos y, más particularmente, a los católicos. En efecto, algunos de ellos exigen un retorno a la fe bíblica pura en el anuncio de la divinidad y la resurrección de Cristo. Sustituyen así la ortodoxia (comprendida como la confesión recta de la fe) por la ortopraxis (comprendida como la práctica recta). Ciertamente, para algunos creyentes la ortopraxis puede estar acompañada de la razón, si bien está reducida a la forma que le da el catecismo o ciertos manuales diseñados como cajas de herramientas. La razón como tal no estaría en posición de alcanzar por ella misma una verdad universal. Alejándose del "gusto de la reflexión" (Benedicto XVI, "La voix éloquente et claire de la conscience", en La documentation catholique, 15 de abril de 2007, p. 357), esos creyentes conciben la razón filosófica como una pérdida de tiempo o, a lo sumo, como un simple instrumento que propone argumentos que se dirigen en un sentido determinado. Tal actitud, que uno podría calificar de fideísmo y que está hoy bastante presente entre los fieles, es defendida incluso en nombre de la espiritualidad, cuando, en realidad, distorsiona profundamente a la persona que se define por el uso de la razón en su autonomía, proponiendo un criterio que, contrariamente a una concepción de la razón ilustrada, es esclarecido para el creyente por medio de la fe y de la tradición de la Iglesia y, a fin de cuentas, mediante la escucha y la obediencia al Logos encarnado. La actitud fideísta de rechazo de un auténtico pensamiento autónomo elaborado a la luz de la fe (por miedo, pereza, comodidad o espiritualidad incorpórea), conduce a la persona a adherirse a las creencias de una manera irracional, mezclada con un moralismo sentimental. 
todo", ${ }^{68}$ para retomar las palabras de Martin Heidegger. Esta actitud se ha hecho común en los albores del siglo XXI. Filosofar consistiría, principalmente, en llevar a cabo un análisis de las fuentes de un pensador, del contexto en el que surgen sus ideas, de la coherencia de su pensamiento a lo largo de su obra; en síntesis, la filosofía quedaría confinada en un museo histórico, mientras que se pondría entre paréntesis la cuestión de la verdad de su pensamiento. ${ }^{69}$ La filosofía ya no existiría, señala Philippe LacoueLabarthe, salvo en la forma de una "tradición cerrada a partir de ahora", que "ya no designa más que el comentario de la filosofia". ${ }^{70} \mathrm{El}$ abandono de la búsqueda de la verdad por sí misma a favor de lo que Mattéi llama el "mandato historicista"71 y relativista, en el cual todas las posiciones se valen, pone en riesgo la razón y abre la posibilidad que se reduzca a una simple actividad instrumental. Tal reducción disminuye el discurso racional ético al rango de la preferencia subjetiva, y por tanto, relativa, al elaborar una ética secular desprovista de contenido moral que se forma en torno al principio de tolerancia de éticas particulares como lo propone, por ejemplo, Tristram Engelhardt. La razón universal parece haber renunciado a la esfera ética y política; queda, a partir de ahora, reducida a la razón instrumental.

La "liberación" de la razón que no está obligada a tender hacia la verdad, particularmente la verdad moral y antropológica, es - recalca Joseph Ratzinger — "una liberación orientada hacia la tiranía", ${ }^{72}$ a lo que podemos añadir: hacia la ley del más fuerte y de la arbitrariedad. En efecto, fue la ausencia de un verdadero juicio moral crítico, descrita por Arendt como la "pura ausencia de pensamiento" — a diferencia de la estupidez_-, la que permitió a Eichmann convertirse

${ }^{68}$ Martin Heidegger, Die Frage nach dem Ding. Zu Kant's Lehre von den transzendentalen Grundsätzen, 1984, Fráncfort, Vittorio Klostermann, p. 99.

${ }^{69}$ Siguiendo a Clive Staple Lewis, podríamos calificar esta actitud como el "punto de vista histórico". The screwtape letters, 1982, Nueva York, MacMillan, pp. 128-129.

${ }^{70}$ Philippe Lacoue-Labarthe, La fiction du politique. Heidegger, l'art et la politique, 1987, París, Christian Bourgeois, p. 14.

${ }^{71}$ Jean-François Mattéi, "Préface", en Josef Pieper, De la divine folie. Sur le Phèdre de Platon, 2006, Ginebra, Ad Solem, p. 8.

${ }^{72}$ Ratzinger, Kirche, Ökumene und Politik, p. 194. 
en aquello que fue: "uno de los más grandes criminales de su tiempo". ${ }^{73}$ Por el contrario, la oposición a la instauración de un sistema totalitario recae en la posibilidad de un juicio racional como parte de un auténtico diálogo interior caracterizado por un discernimiento del yo respecto a una alteridad que lo trasciende. Tal preocupación por el diálogo de la conciencia dirigida hacia el conocimiento racional que aspira a la verdad debe ser colocada "más alto que toda instancia social o forma de inclinación personal"; 74 en la medida en que no sea "una cuestión de gusto o de deseos personales, no coincide con un oportunismo social, un consenso de grupo, reivindicaciones de orden político o poder social". ${ }^{75}$ La conciencia que rechaza a priori una auténtica autocrítica respecto a una alteridad transubjetiva - como lo expresa la tesis de la opinión según la cual todo se vale - puede expresar una mala fe que tiene "una apariencia de seguridad racional" y que es el "fruto de la autojustificación, del conformismo o de la indolencia". ${ }^{76}$ Esta actitud puede ser la consecuencia de un "puro reflejo condicionado por el entorno social" para poder "corresponder a la mentalidad que ahí prevalece" mando las palabras de Philippe Bénéton, la consecuencia de un "conformismo [...] que nutre el deseo de integrarse, la pereza de espíritu o la timidez intelectual", ${ }^{78}$ que Schockenhoff describe como una "dulce manipulación". ${ }^{79}$

A partir de lo anterior, el fundamento de una auténtica libertad en oposición a la ideología del poder del más fuerte (que expresa, paradóji-

${ }^{73}$ Hannah Arendt, Eichmann in Jerusalem, Postscript, 2006, Nueva York, Penguin Books. “[Eichmann] no era estúpido. Fue la pura ausencia de pensamiento — algo para nada idéntico a la estupidez - lo que lo predispuso a convertirse en uno de los más grandes criminales de su época. Y si eso es 'banal' e incluso cómico, si, con la mejor voluntad del mundo, uno no alcanza a descubrir en Eichmann la menor profundidad diabólica o demoniaca, eso no significa ni mucho menos que sea ordinario. [...] Que uno pueda estar hasta ese punto alejado de la realidad, hasta ese punto desprovisto de pensamiento, y que eso pueda causar más mal que todos los malos instintos reunidos, que son tal vez inherentes al hombre, tal era efectivamente la lección que uno podía aprender en Jerusalén”; pp. 287-288.

${ }^{74}$ Ratzinger, Wahrheit, Werte, Macht, pp. 44-45.

${ }^{75}$ Ibid., p. 45.

${ }^{76}$ Ibid., p. 39.

${ }^{77}$ Ibid., p. 37.

${ }^{78}$ Philippe Bénéton, Les Fers de l'opinion, 2000, París, Presses Universitaires de France, p. 17.

${ }^{79}$ Schockenhoff, Wie gewiss ist das Gewissen?, p. 46. 
camente, una libertad esclavizada) permitiría justificar de manera transhistórica y transcultural la condenación de una conciencia infractora como la de Adolf Eichmann. Sin embargo, tal fundamento no puede establecerse más que en el terreno fértil de una ampliación de la noción misma de la razón humana que invertiría las esferas política y ética con la pretensión de alcanzar una verdad que no se erigiera en sistema.

\section{La conciencia moral y el descentramiento de uno mismo}

El llamado al final de la Segunda Guerra Mundial a recentrarse legítimamente en la conciencia personal subjetiva, descentrándose de una conciencia del "nosotros" impersonal o de un "yo" extranjero, ejemplificado por Adolf Hitler, que esclaviza al sujeto, debe venir acompañado siempre, en segunda instancia, por un descentramiento del sujeto en dirección de una alteridad que le permita fundamentar el contenido de su conciencia. Tal descentramiento puede resultar un escape de la interioridad del sujeto hacia el "dicen que", la curiosidad, la dispersión, la inestabilidad y la ansiedad, conceptos que Martin Heidegger analizó finamente. ${ }^{80}$ Por ejemplo, el sujeto reposa la mirada sobre la realidad, ya no para asir la verdad del mundo, sino para estar con ella "en una relación de ser con la cosa vista, que busca el ver tan solo por ver". ${ }^{81}$ El filósofo alemán precisa que la curiosidad,

si busca lo nuevo, es solo para saltar nuevamente desde eso nuevo a otra cosa nueva. En este ver, el cuidado no busca una captación [de las cosas], ni tampoco estar en la verdad mediante el saber, sino que en él procura posibilidades de abandonarse al mundo. Por eso, la curiosidad está caracterizada por una típica incapacidad de quedarse en lo inmediato. Tampoco busca, por consiguiente, el ocio del detenerse contemplativo, sino más bien la inquietud y la excitación de lo siempre nuevo y los cambios de lo que comparece. En esa incapacidad de quedarse en las cosas, la curiosidad

${ }^{80}$ Martin Heidegger, Ser y tiempo, 2003, Madrid, Trotta, trad. de Jorge Eduardo Rivera, pp. 190-195.

${ }^{81}$ Ibid., p. 194. 
busca la constante posibilidad de la distracción. La curiosidad no tiene nada que ver con la contemplación admirativa del ente [...], no está interesada en que el asombro la lleve a un no-comprender; más bien procura un saber, pero tan solo para haber sabido. Los dos momentos constitutivos de la curiosidad, la incapacidad de quedarse en el mundo circundante y la distracción hacia nuevas posibilidades, fundan el tercer carácter esencial de este fenómeno, que nosotros denominamos la carencia de morada. La curiosidad se halla en todas partes y en ninguna. Esta modalidad del estar-en-el-mundo revela un nuevo modo de ser del Dasein cotidiano, en el que este se desarraiga constantemente. ${ }^{82}$

Esta multitud de miradas furtivas desemboca en una superficialidad de imágenes que tiende a monopolizar todo el contenido de la existencia del sujeto. El zapping que caracteriza en nuestros días el uso sensacionalista de la prensa o de la televisión constituye el mejor ejemplo de esa mirada superficial, de esta curiosidad hipertrofiada respecto a lo que el vecino dice y hace. Así, el ser humano se aleja en cierta forma de su ser más profundo o, incluso, lo ahoga. Josef Pieper describe esta vida en la periferia de sí misma como

el ruido que vuelve sordo a quien no hace otra cosa más que trabajar, en el ajetreo exigente del hacedor de palabras sofistas, en la "distracción" incesante prodigada de cosas encantadoras y vacías — en una palabra, en un "no man's land" que podría organizarse cómodamente, pero que no dejaría lugar alguno para la calma de una actividad en sí plena de sentido, para la contemplación, y mucho menos aún para el regocijo. ${ }^{83}$

La persona que existe en la periferia de su ser se determina (y paradójicamente cree que es libre) según aquello que "se dice", "se piensa", "se hace". Esta dictadura del "se" que no es nadie dispensa a la persona de vivir auténticamente aquello que podría ser, una actitud que Martin Heidegger califica de "decadente".

${ }^{82}$ Ibid., p. 195.

${ }^{83}$ Josef Pieper, "Zustimmung zur Welt. Eine Theorie des Festes", en Werke in acht Bänden, 1999, Hamburgo, Felix Meiner, vol. 6, p. 238. 
Esta huida en la esfera del "se" viene con un vaciamiento de las palabras de su fuerza original enraizada en la sustancia misma de la realidad, para otorgarles un sentido relativo con el que se llega incluso a hacer el elogio de un acto moral intrínsecamente malo. En adelante, la palabra no es más que la expresión de una creación subjetiva, de un utensilio de manipulación y de poder, como subraya Philippe Breton, ${ }^{84}$ en la cual el interlocutor no es ya percibido como un alter ego y un compañero, sino como un "objeto" al que hay que convencer, manipular y dominar. La palabra desligada de las normas de la realidad es no solo indiferente a la verdad, sino que igualmente está privada de un interlocutor. Un arte que se expresara, como señaló Josef Pieper en 1964, por medio del "lenguaje público, mediático" y que estuviera,

por principio, neutralizado en oposición a toda norma de verdad, se encontraría entonces, por naturaleza, listo para servir de instrumento a cualquier gobernante que quisiera utilizarlo a su gusto para ejercer su poder. Porque el lenguaje público, separado de las normas de la verdad, crea él mismo, en la medida en que gana terreno, una atmósfera de vulnerabilidad y de disponibilidad epidémica ante el reinado del tirano. ${ }^{85}$

El filósofo de Münster subraya veinte años después de la Segunda Guerra Mundial, y ante el ascenso del relativismo moral, que la actitud de los sofistas es de una "actualidad aterradora" en la medida en que

el hombre promedio ha llegado, en efecto, al punto en el que no solamente no puede encontrar la verdad, sino que tampoco puede buscarla porque le bastan la ilusión y el engaño. Al ser estos últimos los que determinan

${ }^{84}$ Cfr. Philippe Breton, La parole manipulée, 1997, París, La Découverte.

${ }^{85}$ Pieper, "Missbrauch der Sprache - Missbrauch der Macht", en Werke in acht Bänden, 1999, Hamburgo, Felix Meiner, vol. 6, pp. 145-146. Al referirse explícitamente a este opúsculo, Joseph Ratzinger precisa que "negar la capacidad de la verdad en el hombre conduce de entrada a un uso puramente formalista de las palabras y los conceptos que desemboca en un juicio que también es puramente formalista hoy como ayer. [...] Hemos llegado ahora al punto de combustión: ahí donde el contenido ya no cuenta más, el reinado de la praxis pura se instaura de modo que la potencialidad deviene en la norma última. En otras palabras, el poder se impone por doquier como categoría dominante". Ratzinger, Wahrheit, Werte, Macht, pp. 47-48. 
sus convicciones, el hombre queda satisfecho, de ahora en adelante, con una realidad ficticia creada intencionalmente por medio del abuso del lenguaje. ${ }^{86}$

El verdadero descentramiento de sí, consistente en abrirse a una alteridad, exige romper relaciones con el "se", así como con la afirmación según la cual las palabras no son sino expresiones ficticias para respaldar la actitud de la "manía", ${ }^{87}$ que Platón describe como una salida de sí mismo mediante la cual el sujeto renuncia a su suficiencia autárquica y se deja deleitar por la alteridad de lo real, con la idea de conocer "el último Fundamento del mundo". ${ }^{88}$ Este abandono a la receptividad contemplativa, que Martin Heidegger llama "pensamiento meditativo", 89 es ejemplificado por la poesía en la que el eros (cuyo fundamento viene de otra parte, como subraya Jean-Luc Marion $)^{90}$ se distingue de la receptividad perezosa, ejemplificada por "el activismo" del "entretenimiento por el entretenimiento mismo", acompañado por una sobrevaloración del "trabajo por el trabajo" que se convierte en la norma suprema de una vida personal próspera. El llamado a aprobar la actitud de la "manía" platónica, ese éxtasis surgido del verdadero ocio y del regocijo, ${ }^{91}$ es percibido por el "técnico de la vida" 92 y de la "cultura" del entretenimiento como una cosa en suma "absurda y ajena, totalmente imprevista $\mathrm{y}$, a fin de cuentas, moralmente inconveniente: el ocio no sería, de hecho,

${ }^{86}$ Pieper, "Missbrauch der Sprache - Missbrauch der Macht", p. 148.

${ }^{87}$ Véase Josef Pieper, "Begeisterung und göttlicher Wahnsinn. Über den platonischen Dialog 'Phaidros'”, en Werke, 2002, Hamburgo, Felix Meiner, vol. 1, pp. 248-331.

${ }^{88}$ Ibid., p. 304.

${ }^{89}$ Martin Heidegger, Serenidad, 2002, Barcelona, Del Serbal, trad. de Ives Zimmermann, p. 19.

${ }^{90}$ Véase Jean-Luc Marion, Le Phénomène érotique. Six méditations, 2003, París, Grasset.

${ }^{91}$ Cfr. Pieper, "Zustimmung zur Welt. Eine Theorie des Festes".

${ }^{92}$ Pieper, "Begeisterung und göttlicher Wahnsinn", p. 305: "la manía, la salida de uno mismo, el entusiasmo, no solamente no se oponen en nada a la dignidad esencial del hombre, sino que pertenecen más bien a toda existencia humana. Por lo mismo, consiste en haber tomado de entrada una postura en contra de la falsa racionalidad del 'técnico de la vida', de aquel que, cuando se habla delante de él del entusiasmo, sonríe con un aire de superioridad y no anhela la satisfacción de las necesidades humanas, ya sean económicas, afectivas o incluso 'espirituales', más que por medios 'eficientes' y, sobre todo, fáciles y asegurados al máximo contra todo imprevisto". 
más que una máscara para la pereza, otro término para la morbidez y la holgazanería". ${ }^{93}$

El predominio de actividades serviles y propiciadoras de una "nueva cultura" del activismo útil, que suprime la diferencia entre los días feriados — propios de una postura contemplativa — y los días de trabajo — de transformación operacional del mundo-, ha sido descrita por Ratzinger, siguiendo a Josef Pieper, como "la amenaza de nuestros tiempos" o incluso como el "peligro más mortal" ${ }^{94}$ Martin Heidegger subraya igualmente el peligro, que considera por otro lado como mucho más grande que el riesgo de una tercera guerra mundial atómica, de negar el pensamiento meditativo en beneficio de una actitud de indiferencia respecto a este en nombre del "pensamiento calculador", ${ }^{5}$ instrumental u operacional, que pretende afirmarse como el único que puede ejercerse, ${ }^{96}$ con - como señala Pieper — "una forma peculiar de sometimiento intelectual"97 como consecuencia. Pieper agrega que

cuanto más amenace la pretensión por lo absoluto del criterio único de utilidad con propagarse a toda la existencia, más tiene necesidad el ser humano - a fin de vivir de manera auténticamente humana - de disponer de la posibilidad de deshacerse del alboroto sonoro y visual ("compra esto", "bebe aquello", "come esto", "diviértete aquí", "manifiéstate a favor o en contra de esto"), de esos gritos que lo interpelan sin descanso, para preferir un lugar donde domine el silencio y donde sea posible una verdadera escucha, es decir, la percepción de la realidad en la que repose nuestro ser y gracias a la cual este se nutra y se renueve constantemente. ${ }^{98}$

${ }^{93}$ Josef Pieper, "Muße und Kult", en Werke, 1999, Hamburgo, Felix Meiner, vol. 6, p. 20.

${ }^{94}$ Joseph Ratzinger, Im Anfang schuf Gott. Vier Predigten über Schöpfung und Fall. Konsequenzen des Schöpfungsglaubens, 1996, Einsiedeln, Johannes Verlag, p. 43.

${ }^{95}$ Martin Heidegger, Serenidad, p. 19.

${ }^{96}$ Loc. cit. Véase también Taylor, The sources of the self.

${ }^{97}$ Josef Pieper, "Erkenntnis und Freiheit", en Werke, 2008, Hamburgo, Felix Meiner, vol. 8.2, p. 441.

${ }^{98}$ Josef Pieper, "Was ist eine Kirche?", en Werke, 2000, Hamburgo, Felix Meiner, vol. 7, p. 555. Ratzinger se refiere explícitamente en reiteradas ocasiones a Pieper. Cita este pasaje en Dogmatik und Verkündigung (1973, Múnich/Friburgo, Erich Wewel Verlag, p. 270). Véase también al respecto la tesis según la cual "la palabra proviene de la plenitud del silencio y que este le confiere su legitimidad”. Max Picard, Die Welt des Schweigens, 1988, Múnich, R. Pieper, p. XII. 
Para ser verídico, sin embargo, lo que se entiende durante el éxtasis o la "manía" platónica debe estar fundado en el discurso racional argumentativo. Si tal fundamento se aceptara como imposible, no estaríamos en capacidad de diferenciar un discurso verdadero de uno falso. Tampoco podríamos, en definitiva, declarar que una conciencia es infractora; dicho de otra manera, nos veríamos obligados a afirmar que toda acción humana es, en última instancia, legítima. Daríamos por vencida la esfera moral en aras de la de la ley del más fuerte y de lo arbitrario. No podríamos ya considerar la afirmación del abogado de Eichmann, quien reduce la moral a las costumbres relativas al sujeto o a una comunidad de sujetos, como "increíble". 99

\section{Conclusión}

El baluarte erigido a finales de la Segunda Guerra Mundial contra la tentación de sucumbir a un nuevo totalitarismo solo es eficaz si prolongamos, siguiendo a John Henry Newman, el llamado imperativo a seguir la conciencia, cualesquiera que sean las circunstancias. No obstante, a fin de no caer en el totalitarismo de la subjetividad comprendida como única instancia ética, este llamado debe venir con dos nociones igualmente necesarias. Por un lado, un descentramiento de sí mismo que se opera por la intermediación de una escucha silenciosa de la alteridad del mundo, ejemplificada por la "manía" platónica que no se deja engullir por la razón instrumental. Ahora bien, este pensamiento mediador no es suficiente. El caso de Martin Heidegger, quien defiende la importancia de semejante pensamiento contemplativo en oposición a su relación con el partido nazi es, para este tema, revelador. Por el otro lado, resulta urgente desaprender a "pensar por delegación", ${ }^{100}$ como señala Emmanuel Mounier, con el fin de adquirir cierto rigor de pensamiento, de juicio, y de hacer que se produzca un auténtico diálogo racional con la esperanza de conocer la verdad. Tal descentramiento no es cosa fácil de emprender.

${ }^{99}$ Arendt, Responsability and judgement, p. 43.

${ }^{100}$ Emmanuel Mounier, Manifeste du personnalisme, 1936, París, Aubier, p. 99. 
En su búsqueda de la verdad, el sujeto es proyectado sobre una "ruta empinada", ${ }^{101}$ en una empresa "laboriosa y dolorosa", ${ }^{102}$ como la alegoría platónica de la caverna lo da a entender. Esta búsqueda abarca igualmente los dominios éticos y políticos, eminentemente personales y existenciales.

El llamado a la permanente conversión de la conciencia personal a fin de oponerse al totalitarismo tropieza, no obstante, con una dificultad real, ejemplificada por el caso de Martin Heidegger, y que reside en el poder de la esfera del "se" y de la palabra tal como fue manipulada por el régimen nazi. Platón describe una situación análoga cuando rinde cuentas de la actitud de Sócrates en oposición a la de Trasímaco o la de Calicles. Este último afirma que aquel que pone en práctica la posición filosófica de Sócrates se vuelve "peor que como era antes"103 y "merece ser golpeado"; 104 uno "tiene el derecho de pegarle en la cabeza impunemente" 105 o incluso de matarlo. Es considerado como un loco y un idiota, así como Apolodoro en El banquete de Platón o Tales en el Teeteto. Sin embargo, la actitud de Sócrates expresa la humildad de la razón que espera alcanzar la verdad en un contexto en el que tiene todo el poder la ideología de la ilusión que procuran las palabras cuyo contenido es definido por el sujeto. El seudodiálogo entre Trasímaco y Sócrates en el primer libro de La república expresa de maravilla la negativa que el interlocutor opone a una escucha auténtica de lo real, investido como está por el poder que poseen las palabras que llevan al poder político. ¿Qué hacer ante esa tiranía? Sócrates escoge ser quien es presentándose - humildemente - como el modelo de mártir del logos que afirma, contra viento y marea, la capacidad de la razón humana para dejarse raptar por la verdad, "para alinearse — precisa Josef Pieperen pensamiento y en palabras con aquello que es real". ${ }^{106}$ Su negativa a someterse al mandato del historicismo y del poder, su perseverancia

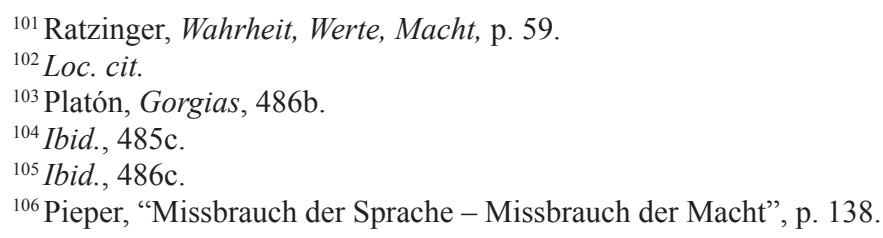


en su laboriosa búsqueda racional y llena de esperanza de conocer la verdad sobre el mundo y el ser humano lo llevó a convertirse en mártir del logos y, así, en testigo de la conciencia. Después de haber afirmado que el siglo XXI se encuentra frente a "la tentación" de establecer una situación a la vez similar e idéntica a la del régimen nazi, Ratzinger subraya que

solo aquel que es ciego, o que quiere serlo por comodidad, puede dejar de percibir que la amenaza totalitaria es un problema de nuestro tiempo. En ese sentido, nuestro siglo es un siglo de la conciencia. Es la razón por la que los hombres que han obedecido a su conciencia y que se han mantenido firmemente del lado de la libertad de la conciencia contra la "liberación" totalitaria nos interpelan hoy en día de una manera totalmente nueva. ${ }^{107}$

${ }^{107}$ Ratzinger, Kirche, Pokumene und Politik, p. 155. Se encuentra una convicción similar en el filósofo Georges Cottier, quien afirma - al mismo tiempo que apela a la educación de la conciencia, la cultura y el criterio - la importancia de la "presencia de auténticas personalidades, responsables y coherentes en la fidelidad a los valores fundamentales, cuya cultura vive y con ella, la sociedad. Lo que importa es el testimonio de verdaderas personalidades morales". Georges Cottier, Questions de la modernité, 1985, París, Fac, pp. 69-70. 
Se prohíbe su reproducción total o parcial por cualquier medio, incluido electrónico, sin permiso previo y por escrito de los editores. 